Article

\title{
On the Fragility of Bulk Metallic Glass Forming Liquids
}

\author{
Isabella Gallino \\ Department of Materials Science and Engineering, Saarland University, Campus C6.3, 66123 Saarbrücken, \\ Germany; i.gallino@mx.uni-saarland.de; Tel.: +49-681-302-2052
}

Received: 25 August 2017; Accepted: 7 September 2017; Published: 10 September 2017

\begin{abstract}
In contrast to pure metals and most non-glass forming alloys, metallic glass-formers are moderately strong liquids in terms of fragility. The notion of fragility of an undercooling liquid reflects the sensitivity of the viscosity of the liquid to temperature changes and describes the degree of departure of the liquid kinetics from the Arrhenius equation. In general, the fragility of metallic glass-formers increases with the complexity of the alloy with differences between the alloy families, e.g., Pd-based alloys being more fragile than Zr-based alloys, which are more fragile than Mg-based alloys. Here, experimental data are assessed for 15 bulk metallic glasses-formers including the novel and technologically important systems based on $\mathrm{Ni}-\mathrm{Cr}-\mathrm{Nb}-\mathrm{P}-\mathrm{B}$, Fe-Mo-Ni-Cr-P-C-B, and Au-Ag-Pd-Cu-Si. The data for the equilibrium viscosity are analyzed using the Vogel-Fulcher-Tammann (VFT) equation, the Mauro-Yue-Ellison-Gupta-Allan (MYEGA) equation, and the Adam-Gibbs approach based on specific heat capacity data. An overall larger trend of the excess specific heat for the more fragile supercooled liquids is experimentally observed than for the stronger liquids. Moreover, the stronger the glass, the higher the free enthalpy barrier to cooperative rearrangements is, suggesting the same microscopic origin and rigorously connecting the kinetic and thermodynamic aspects of fragility.
\end{abstract}

Keywords: bulk metallic glasses; fragility; specific heat capacity; viscosity; configurational entropy; activation energy

\section{Introduction}

Starting from the early 1990s, several bulk metallic glass (BMG) compositions with critical casting thickness greater than $1 \mathrm{~mm}$ and robust supercooled liquid against crystallization were discovered [1-7]. These BMG-formers are multicomponent alloys based on transition metals like $\mathrm{Zr}, \mathrm{Cu}, \mathrm{Fe}, \mathrm{Ni}, \mathrm{Mg}$, $\mathrm{Pd}, \mathrm{Pt}, \mathrm{Au}$, and $\mathrm{La}$ and with a large size mismatch between the constituents. Among these, the $\mathrm{Zr}$-Ti-Cu-Ni-Be system was among the first commercial BMG alloy [8], followed soon after by many beryllium-free composition in the $\mathrm{Zr}-\mathrm{M}-\mathrm{Cu}-\mathrm{Ni}-\mathrm{Al}$ alloy system, with $\mathrm{M}=\mathrm{Nb}$ or $\mathrm{Ti}$ [3,9-11]. Recently, the nickel system Ni-Cr-Nb-P-B [7], the steel system Fe-Mo-Ni-Cr-P-C-B [6], and the gold system $\mathrm{Au}-\mathrm{Ag}-\mathrm{Pd}-\mathrm{Cu}-\mathrm{Si}[5,12]$ have captured the attention of researchers and manufacturers because they are technologically very promising: the first two as structural materials due to the low cost of the constituents and the latter as 18-karat premium-white gold jewelry alloy.

Many BMG compositions can be cast with a thickness up to $30 \mathrm{~mm}$ by conventional casting due to their excellent glass forming ability (GFA). The GFA is defined as the facility of the melt to bypass crystallization and to freeze into a glass. A common characteristic of high-GFA of BMGs is the location at time greater than $100 \mathrm{~s}$ of the nose of the nucleation curve in the time temperature transformation (TTT) diagram [13]. This ability results from the interplay between the thermodynamic and the kinetics properties of the undercooled liquid. In fact, the shape of the nucleation curve in the TTT diagram for BMGs is connected, on one side, to their low driving force for crystallization, represented by the Gibbs 
free energy difference between the undercooled melt and the crystal. This derives from relatively small heat and entropy of fusion values, which are typical for BMG-formers and that are much lower than that for conventional glass formers [14,15], indicating that BMG-forming compositions are thermodynamically closer to the crystalline state [16]. On the other side, the low diffusivities of the different metallic constituents result in high melt viscosity [15]. The effect of the sluggish kinetics in BMG-forming melts frustrates the nucleation and growth of crystals, thereby retarding the formation of the equilibrium crystalline state upon undercooling. The robustness of the deeply undercooled liquid state of the BMG compositions with respect to crystallization has allowed for systematic studies of the thermo-physical properties such as specific heat capacity and viscosity of these liquids in the ultra-high viscous state in a broad time and temperature range before the onset of crystallization [17-23].

Among glass-forming liquids, the temperature dependence of viscosity can vary considerably. While some liquids follow an Arrhenius law (e.g., $\mathrm{SiO}_{2}$ ), others, like the $\mathrm{BMGs}$ and polymeric systems, display highly non-Arrhenius behavior. A quantitative description of the diversity of kinetic behavior is the notion of fragility as proposed by Angell [24], which quantifies the temperature dependence of viscosity, and can be described by the Vogel-Fulcher-Tammann (VFT) equation

$$
\eta(T)=\eta_{0} \exp \left[D^{*} T_{0} /\left(T-T_{0}\right)\right],
$$

where $\eta_{0}$ is the infinite-temperature limit of viscosity, calculated as $\eta_{0}=\left(N_{A} h / V\right), N_{A}$ is Avogadro's constant, $\mathrm{h}$ is the Planck constant, and $\mathrm{V}$ is the molar volume. $\mathrm{T}_{0}$ is the temperature at which barriers to viscous flow in the supercooled liquid would approach infinity. $\mathrm{D}^{*}$ is the kinetic fragility parameter and describes the deviation from the Arrhenius behavior. The smaller the $\mathrm{D}^{*}$, the more kinetically fragile the liquid. Fragility can be alternatively represented by the steepness index $m$, defined as the logarithmic slope of viscosity at the glass transition temperature, $T_{g}: m=d \log (\eta(T)) / d\left(T_{g} / T\right)$ at $\mathrm{T}=\mathrm{T}_{\mathrm{g}}$ [24]. Smaller $m$ values correspond to stronger behavior. The BMG-formers exhibit, in the deeply undercooled state, intermediate kinetic fragilities between the strong network glass-former $\mathrm{SiO}_{2}\left(\mathrm{D}^{*}>100\right)$ and the fragile glass-former o-therphenyl $\left(\mathrm{D}^{*}=2\right)$ with a $\mathrm{D}^{*}$ parameter that ranges between 10 and 26 [25] and a $m$ value between 40 and 80 . Important questions arise as to whether slow kinetics is found in BMG formers in general and how it depends on, for example, the alloy composition, the alloy complexity, and the group of alloys.

The viscosity increase with undercooling in BMG-forming liquids is a purely kinetic phenomenon, which is considered to be connected to the underlying thermodynamics of the system. The idea to connect the kinetic slowdown with the thermodynamics of a glass-forming system is not new, and a considerable amount of research has been performed on this subject, starting from the early work of Adam and Gibbs [26] and Goldstein [27] until recent literature on non-polymeric glass forming liquids of Angell [28]. The relation predicted by Adam and Gibbs between the viscosity and the configurational entropy of the liquid, $\mathrm{S}_{\mathrm{C}}(\mathrm{T})[26]$, is

$$
\eta(T)=\eta_{0} \exp \left[C /\left(\mathrm{TS}_{C}(\mathrm{~T})\right)\right]
$$

Here, $\mathrm{C}$ is a constant that represents the free enthalpy barrier per particle to cooperative rearrangements. $\mathrm{S}_{\mathrm{C}}(\mathrm{T})$ is the configurational part of the entropy, which represents the number of distinct packing states at a certain temperature.

Recently, an empirical model, the Mauro-Yue-Ellison-Gupta-Allan (MYEGA) model [29], has assumed the temperature dependence of the configurational entropy to be $S_{C}(T)=1 / \exp (H / T)$. By inserting this relation in Equation (2), the MYEGA equation is derived as

$$
\eta(T)=\eta_{0} 10^{[(K / T) \exp (H / T)]},
$$


where $\mathrm{K}$ and $\mathrm{H}$ are fitting parameters. $\mathrm{K}$ is an effective activation energy barrier per atom normalized by the number of possible, distinguishable configurations [30-32]. H represents the energy difference for each particle between two configurations normalized by the Boltzmann constant.

The present work attempts to assess the experimental thermodynamic and kinetic data of several bulk metallic glass forming systems in terms of the aforementioned kinetic and thermodynamic fragility concepts. The aim is to assess the low-temperature dynamic regime, i.e., in the vicinity of the glass transition temperature. This is because the majority of metallic glass-forming liquids exhibit identical fragile dynamic behaviours above the melting point with $\mathrm{D}^{*}$ values of $\sim 10$, but a range of stronger effective fragilities from $\mathrm{D}^{*}$ value of 10 to 26 when measured in the ultra-viscous state, as a result of an entropy-driven fragile-to-strong transition during undercooling [20,33-41]. Systematic and consistent fitting procedures of the equilibrium viscosity data within this temperature regime are performed using the VFT, MYEGA, and Adam-Gibbs equations. The results prove the existence of a direct correlation between the activation energy for cooperative rearrangements in the ultra-high viscous state and the kinetic fragility parameter.

\section{Materials and Methods}

The study is carried out on 15 BMG compositions with high or excellent GFA. The selected compositions are listed in the Tables. For each composition, plates of dimensions $3 \times 13 \times 35 \mathrm{~mm}$ were produced by casting the master alloys into a water-cooled $\mathrm{Cu}$-mold using a tilt-casting apparatus (MC15, Indutherm GmbH, Walzbachtal, Germany). The preparation of the master alloys required a variety of processing methods that are described in [19,21,22,33,42-45]. The P-containing master alloys were purified in a flux of $\mathrm{B}_{2} \mathrm{O}_{3}$ prior to casting. To prevent room temperature aging of the material, the $\mathrm{Au}$ - and the $\mathrm{Mg}$-based samples were stored in a freezer at roughly $-18{ }^{\circ} \mathrm{C}$, and the time spent out of the freezer for machining or experiments was minimized. Prior to experiments all as-cast products were shown to be X-ray amorphous and homogenous.

Differential scanning calorimetry was carried out under a constant argon flow in a power-heat compensated DSC (Hyper DSC8500, PerkinElmer Inc., Waltham, MA, U.S.A.), equipped with an intracooler and calibrated according to the melting transitions of n-decane $\left(\mathrm{C}_{10} \mathrm{H}_{22}\right)$, indium, tin, and zinc, and to the thermal phase transformation of $\mathrm{K}_{2} \mathrm{SO}_{4}$. The absolute value of the specific heat capacity was determined upon heating in reference to the specific heat capacity of a sapphire standard using a step method described elsewhere [19]. Due to the maximum temperature limit of the DSC, the specific heat capacity of the high- $\mathrm{T}_{\mathrm{g}}$ compositions was measured continuously in a differential thermal analyzer (STA449 Jupiter, NETZSCH GmbH, Selb, Germany) [22,23].

The equilibrium viscosities in the vicinity of the glass transition were determined by isothermal three-point beam bending (ITPBB) experiments using a thermomechanical analyzer (TMA402, NETZSCH GmbH, Selb, Germany). Amorphous beams with rectangular cross-sectional areas of 0.3 to $1.1 \mathrm{~mm}^{2}$ and a length of $13 \mathrm{~mm}$ were positioned on two sharp supporting edges with span of $1.196 \times 10^{-2} \mathrm{~m}$. A load of $10 \mathrm{~g}$ was centrally applied by a silica probe with a wedge-shaped head, and the samples were heated to the desired temperature with a constant rate of $0.333 \mathrm{~K} \mathrm{~s}^{-1}$. There they were held isothermally at least until the end of the viscosity relaxation process while the beam deflection during relaxation was measured. The resulting viscosity was calculated according to the methodology described in References. [21,22].

\section{Results and Discussion}

\subsection{Thermodynamic and Kinetic Experimental Data}

The analyses of this work rely greatly on accurate measurements of specific heat capacity and equilibrium viscosity, published elsewhere for each selected alloy composition. The corresponding literature is given in the Tables. An example of such data are shown in the plots of Figures 1 and 2, for $c_{p}(T)$ and $\eta(t)$, respectively $[23,42]$. The experimental $c_{p}(T)$ data of Figure 1 were obtained using a 
standard discontinuous step-method with heating rate of $0.333 \mathrm{~K} \mathrm{~s}^{-1}$ and isothermal holding time of $120 \mathrm{~s}$ [42]. The data for the liquid, $l$, the crystal, $x$, and the glass are fitted to the equations reported below, respectively,

$$
c_{\mathrm{p}}{ }^{l}(\mathrm{~T})=3 R+a \mathrm{~T}+b \mathrm{~T}^{-2} ; \mathrm{c}_{\mathrm{p}}{ }^{x}(\mathrm{~T})=3 R+c \mathrm{~T}+d \mathrm{~T}^{2} ; \mathrm{c}_{\mathrm{p}}^{\text {glass }}(\mathrm{T})=(3 R / M)\left(1-\exp \left(1.5\left(\mathrm{~T} / \mathrm{T}_{\mathrm{D}}\right)\right),\right.
$$

where $R$ is the gas constant, $\mathrm{T}_{\mathrm{D}}$ the Debye temperature, $M$ a multiplier [46], and $a-d$ are fitting constants reported elsewhere [23]. In Figure $1, \mathrm{~T}_{\mathrm{liq}}$ is the liquidus temperature, $\mathrm{T}_{\mathrm{g}}{ }^{*}$ and $\mathrm{T}_{\mathrm{m}}{ }^{*}$ are the temperature values, for which the viscosity of the liquid is $10^{12} \mathrm{~Pa} \mathrm{~s}$ and $1 \mathrm{~Pa}$ s, respectively [25].

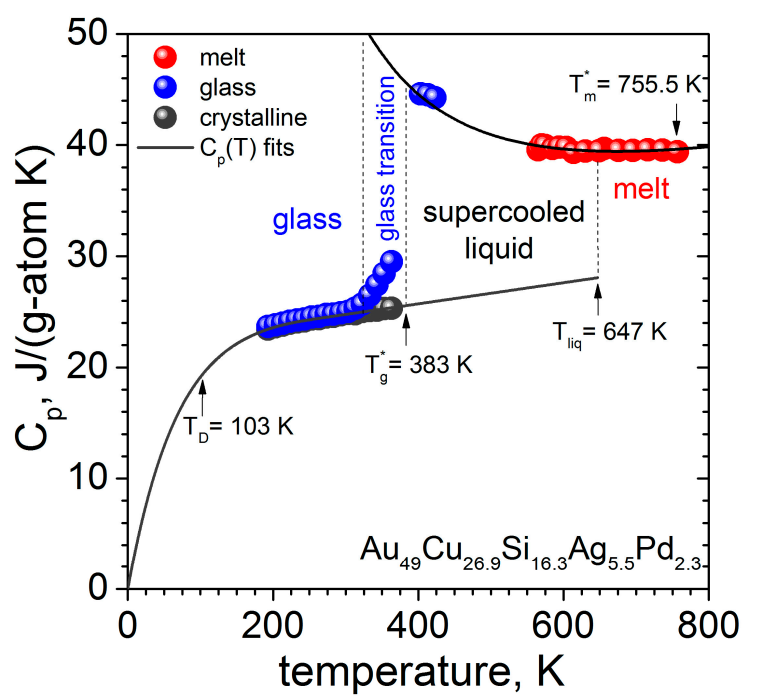

Figure 1. Specific heat capacity plot for the $\mathrm{Au}_{49} \mathrm{Cu}_{26.9} \mathrm{Si}_{16.3} \mathrm{Ag}_{5.5} \mathrm{Pd}_{2.3} \mathrm{BMG}$ composition. The symbols are $C_{p}(T)$ data measured in isothermal steps for the glass, the crystalline solid, the supercooled liquid and the stable liquid (melt). The error bar has the size of the symbols. The curves are the fits to Equations (4). $T_{D}$ marks the Debye temperature; $T_{\text {liq }}$ the calorimetric liquidus temperature; $T_{\mathrm{g}}{ }^{*}$ and $\mathrm{T}_{\mathrm{m}}{ }^{*}$ are the temperature values for which the viscosity of the liquid is $10^{12} \mathrm{~Pa} \mathrm{~s}$ and $1 \mathrm{~Pa}$ s, respectively.

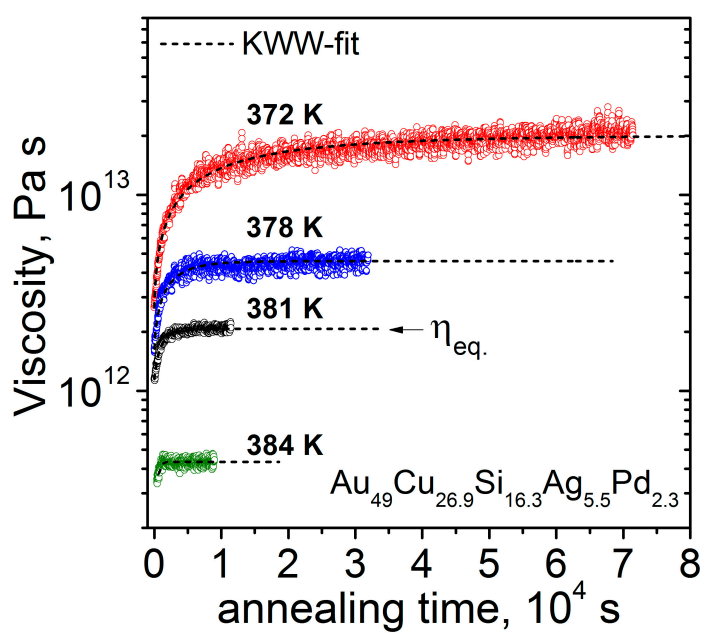

Figure 2. Experimentally determined isothermal viscosities (open circles) for the $\mathrm{Au}_{4} \mathrm{Cu}_{26.9} \mathrm{Si}_{16.3} \mathrm{Ag}_{5.5} \mathrm{Pd}_{2.3}$ BMG composition at annealing temperatures below $\mathrm{T}_{\mathrm{g}}$. The dashed lines are the KWW-fits to the data (Equation (5)) from which the equilibrium viscosity values are obtained. The equilibrium viscosity $\eta_{\text {eq }}$. corresponds to the plateau value reached by the KWW fit for long times. 
In Figure 2 four representative datasets are shown from the standard ITPBB measurements of viscosity $[23,42]$. As the samples begin to relax (age) below $T_{g}$, the measured viscosity rises rapidly, eventually reaching a constant value at longer annealing times. This value corresponds to the equilibrium viscosity of the deeply undercooled liquid, $\eta_{\text {eq. }}$. The experimental data are fitted with a stretched exponential function of the Kohlrausch-Williams-Watts (KWW) type, as follows:

$$
\eta(t)=\eta_{a}+\Delta \eta\left(1-\exp \left[-(t / \tau)^{\beta}\right] .\right.
$$

The initial viscosity of the glassy state just before relaxation is $\eta_{a}$, whereas $\Delta \eta$ is the total viscosity change after relaxation into the equilibrium liquid, $\tau$ is a relaxation time, and $\beta$ is the stretching exponent. The values of $\eta_{\mathrm{eq}}=\Delta \eta-\eta_{\mathrm{a}}$ are plotted on a logarithmic scale against inverse temperature in Figure 3 and are used for the determination of the fragility of the system in the ultra-viscous state.

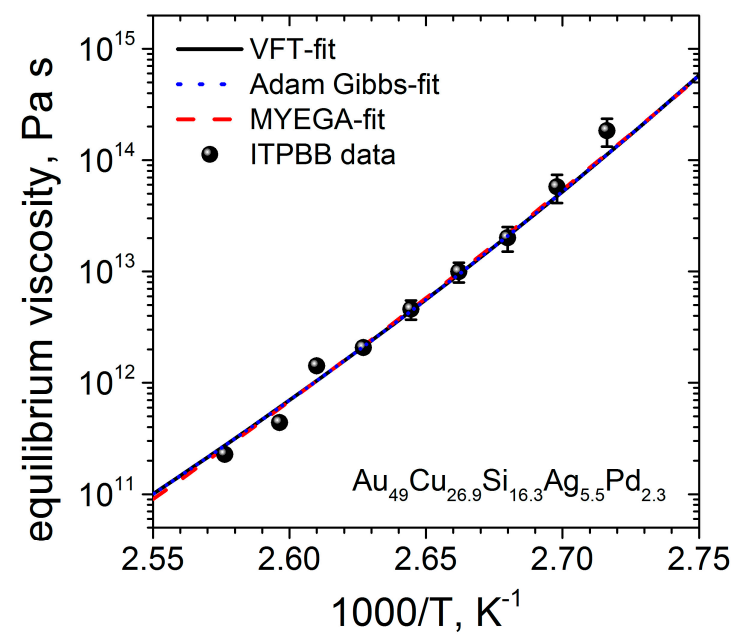

Figure 3. Isothermal equilibrium viscosities of the $\mathrm{Au}_{49} \mathrm{Cu}_{26.9} \mathrm{Si}_{16.3} \mathrm{Ag}_{5.5} \mathrm{Pd}_{2.3} \mathrm{BMG}$ measured by isothermal three-point beam bending at temperatures below the glass transition (open circles) [23,42]. The lines are fits of the VFT, MYEGA, and Adam-Gibbs equation to the experimental data.

\subsection{Fitting Procedures}

Nonlinear fits using the VFT, the Adam-Gibbs, and the MYEGA equations (Equations 1-3) are applied to the experimental equilibrium viscosity data, resulting in the determination of the $\mathrm{C}, \mathrm{D}^{*}, \mathrm{H}$, and $\mathrm{K}$ parameters, respectively. The results of the fitting procedures are listed in the Tables 1-3.

Figure 3 shows, as an example, the equilibrium viscosity data for the $\mathrm{Au}_{49} \mathrm{Cu}_{26.9} \mathrm{Si}_{16.3} \mathrm{Ag}_{5.5} \mathrm{Pd}_{2.3}$ BMG composition, after [23,42]. The VFT fit is shown as a black continuous curve and the Adam-Gibbs-fit as a dotted blue curve. In both models, the viscosity of the deeply undercooled liquid is predicted to diverge at a non-zero temperature. This temperature is denoted as $T_{0}$ in the VFT equation. For the Adam-Gibbs expression, we have defined this temperature as $\mathrm{T}_{0}{ }^{*}$. At this temperature, the configurational entropy of the deeply undercooled liquid would vanish. The value of $\mathrm{T}_{0}$ obtained in this work agrees within 10 degrees with the value of $\mathrm{T}_{0}{ }^{*}$, where $\mathrm{S}_{C}\left(\mathrm{~T}_{0}{ }^{*}\right)=0$ which suggested a link between the kinetics and thermodynamics of viscous flow (see also [25] and next paragraph). The model of a divergence at finite temperatures has been recently questioned [47,48], and the empirical MYEGA equation attempts to avoid the singularity at finite temperatures by assuming an exponential decay of the configurational entropy to $0 \mathrm{~K}$ [29]. Although this difference is fundamental, all three expressions fit the viscosity data around $\mathrm{T}_{\mathrm{g}}$ equally well, as shown in Figure 3. 
Table 1. MYEGA fitting parameters used to model the equilibrium viscosity data taken from the literature (listed in Table 2) to the Equation (3). $T_{g}$ is the standard glass transition temperature in Kelvin at which the undercooled liquid assumes a value of $10^{12} \mathrm{~Pa}$ s, i.e., $\mathrm{T}_{\mathrm{g}}=\mathrm{T}_{\mathrm{g}}{ }^{*}$. H and $\mathrm{K}$ are the MYEGA temperature parameters in units of Kelvin. The $m$ (MYEGA) is fragility parameter based on Equation (3) and calculated as: $\left(\mathrm{K} / \mathrm{T}_{\mathrm{g}}\right)\left(1+\mathrm{H} / \mathrm{T}_{\mathrm{g}}\right) \exp \left(\mathrm{H} / \mathrm{T}_{\mathrm{g}}\right)[29,40]$.

\begin{tabular}{cccccc}
\hline Material (at\%) & $\mathbf{T}_{\mathbf{g}}$ & $\mathbf{K}$ & $\mathbf{H}$ & $\mathbf{K} / \mathbf{H}$ & m(MYEGA) \\
\hline $\mathrm{Mg}_{59.5} \mathrm{Cu}_{22.9} \mathrm{Ag}_{6.6} \mathrm{Gd}_{11}$ & 396.2 & 1447.4 & 598.7 & 2.42 & 41.6 \\
$\mathrm{Mg}_{65} \mathrm{Cu}_{25} \mathrm{Y}_{10}$ & 413.6 & 1513 & 617.0 & 2.45 & 40.5 \\
$\mathrm{Zr}_{46.75} \mathrm{Ti}_{8.25} \mathrm{Cu}_{7.5} \mathrm{Ni}_{10} \mathrm{Be}_{27.5}$ & 597 & 2276.8 & 865.4 & 2.63 & 39.8 \\
$\mathrm{Zr}_{41.2} \mathrm{Ti}_{13.8} \mathrm{Cu}_{12.5} \mathrm{Ni}_{10} \mathrm{Be}_{22.5}$ & 613 & 1080.5 & 1367.9 & 0.79 & 53.1 \\
$\mathrm{Fe}_{67} \mathrm{Mo}_{6} \mathrm{Ni}_{3.5} \mathrm{Cr}_{3.5} \mathrm{P}_{12} \mathrm{C}_{5.5} \mathrm{~B}_{2.5}$ & 717 & 1741.3 & 1360.7 & 1.28 & 46.9 \\
$\mathrm{Au}_{49} \mathrm{Cu}_{26.9} \mathrm{Si}_{16.3} \mathrm{Ag}_{5.5} \mathrm{Pd}_{2.3}$ & 383.3 & 852.8 & 765.1 & 1.12 & 49.1 \\
$\mathrm{Cu}_{47} \mathrm{Ti}_{34} \mathrm{Zr}_{11} \mathrm{Ni}_{8}$ & 658 & 1825.7 & 1162.5 & 1.57 & 44.9 \\
$\mathrm{Zr}_{58.5} \mathrm{Cu}_{15.6} \mathrm{Ni}_{12.8} \mathrm{Al}_{10.3} \mathrm{Nb}_{2.8}$ & 666 & 1173.9 & 1486.1 & 0.79 & 53.0 \\
$\mathrm{Pd}_{40} \mathrm{Ni}_{40} \mathrm{P}_{20}$ & 559 & 1015.0 & 1231.1 & 0.82 & 52.6 \\
$\mathrm{Pt}_{42.5} \mathrm{Cu}_{27} \mathrm{Ni}_{9.5} \mathrm{P}_{21}$ & 498.0 & 732.0 & 1202.0 & 0.61 & 56.1 \\
$\mathrm{Ni}_{69} \mathrm{Cr}_{8.5} \mathrm{Nb}_{3} \mathrm{P}_{16.5} \mathrm{~B}_{3}$ & 652.1 & 773.7 & 1705.5 & 0.45 & 58.6 \\
$\mathrm{Pd}_{40} \mathrm{Cu}_{30} \mathrm{Ni}_{10} \mathrm{P}_{20}$ & 578 & 1020.2 & 1286.7 & 0.79 & 52.8 \\
$\mathrm{Pt}_{57.3} \mathrm{Cu}_{14.6} \mathrm{Ni}_{5.3} \mathrm{P}_{22.8}$ & 479.1 & 436.1 & 1385.9 & 0.32 & 63.9 \\
$\mathrm{Pt}_{60} \mathrm{Cu}_{16} \mathrm{Co}_{2} \mathrm{P}_{22}$ & 487.0 & 268.0 & 1692.0 & 0.16 & 79.5 \\
$\mathrm{Pd}_{43} \mathrm{Cu}_{27} \mathrm{Ni}_{10} \mathrm{P}_{20}$ & 568 & 240.7 & 2072.9 & 0.12 & 75.8 \\
\hline
\end{tabular}

Table 2. VFT fitting parameters used to model the equilibrium viscosity data taken from the indicated literature to Equation (1). $\mathrm{D}^{*}$ is the VFT fragility parameter; $m$ is the fragility steepness index calculated as $\left(\mathrm{D}^{*} \mathrm{~T}_{0} \mathrm{~T}_{\mathrm{g}}{ }^{*}\right) /\left(2.3\left(\mathrm{~T}_{\mathrm{g}}{ }^{*}-\mathrm{T}_{0}\right)^{2}\right) ; \mathrm{T}_{0}$ is the VFT temperature in Kelvin; $\mathrm{T}_{\mathrm{g}}{ }^{*}$ is the standard glass transition temperature in Kelvin at which the undercooled liquid assumes a value of $10^{12} \mathrm{~Pa}$ s. $\eta_{0}$ is the infinite-temperature limit of viscosity in Pa s.

\begin{tabular}{ccccccc}
\hline Material $(\mathbf{a t} \%)$ & $\eta_{\text {eq }}$-Data & $\mathbf{D}^{*}$ & $\boldsymbol{m}$ & $\mathbf{T}_{\mathbf{0}}$ & $\mathbf{T}_{\mathbf{g}}{ }^{*}$ & $\eta_{\mathbf{0}} \times \mathbf{1 0}^{-\mathbf{5}}$ \\
\hline $\mathrm{Mg}_{59.5} \mathrm{Cu}_{22.9} \mathrm{Ag}_{6.6} \mathrm{Gd}_{11}$ & {$[45]$} & 26.0 & 40.7 & 235.3 & 396.2 & 3.1 \\
$\mathrm{Mg}_{65} \mathrm{Cu}_{25} \mathrm{Y}_{10}$ & {$[49]$} & 22.1 & 44.5 & 261 & 413.6 & 4.0 \\
$\mathrm{Zr}_{46.75} \mathrm{Ti}_{8.25} \mathrm{Cu}_{7.5} \mathrm{Ni}_{10} \mathrm{Be}_{27.5}$ & {$[50]$} & 22.1 & 44.2 & 376 & 597 & 4.0 \\
$\mathrm{Zr}_{41.2} \mathrm{Ti}_{13.8} \mathrm{Cu}_{12.5} \mathrm{Ni}_{10} \mathrm{Be}_{22.5}$ & {$[51]$} & 22.0 & 44.4 & 387 & 613 & 4.0 \\
$\mathrm{Fe}_{67} \mathrm{Mo}_{6} \mathrm{Ni}_{3.5} \mathrm{Cr}_{3.5} \mathrm{P}_{12} \mathrm{C}_{5.5} \mathrm{~B}_{2.5}$ & {$[21]$} & 21.3 & 44.7 & 456.5 & 717 & 5.8 \\
$\mathrm{Au}_{49} \mathrm{Cu}_{26.9} \mathrm{Si}_{16.3} \mathrm{Ag}_{5.5} \mathrm{Pd}_{2.3}$ & {$[23,42]$} & 20.9 & 46.2 & 246.9 & 383.3 & 4.0 \\
$\mathrm{Cu}_{47} \mathrm{Ti}_{34} \mathrm{Zr}_{11} \mathrm{Ni}_{8}$ & {$[52]$} & 20.4 & 46.7 & 427 & 658 & 4.0 \\
$\mathrm{Zr}_{58.5} \mathrm{Cu}_{15.6} \mathrm{Ni}_{12.8} \mathrm{Al}_{10.3} \mathrm{Nb}_{2.8}$ & {$[19]$} & 19.7 & 47.5 & 437 & 666 & 4.0 \\
$\mathrm{Pd}_{40} \mathrm{Ni}_{40} \mathrm{P}_{20}$ & {$[53]$} & 15.4 & 55.8 & 396 & 559 & 4.0 \\
$\mathrm{Pt}_{42.5} \mathrm{Cu}_{27} \mathrm{Ni}_{9.5} \mathrm{P}_{21}$ & {$[22]$} & 15.3 & 56.9 & 354.4 & 498.0 & 4.0 \\
$\mathrm{Ni}_{69} \mathrm{Cr}_{8.5} \mathrm{Nb}_{3} \mathrm{P}_{16.5} \mathrm{~B}_{3}$ & {$[22]$} & 14.9 & 57.1 & 466.3 & 652.1 & 5.9 \\
$\mathrm{Pd}_{40} \mathrm{Cu}_{30} \mathrm{Ni}_{10} \mathrm{P}_{20}$ & {$[54]$} & 14.5 & 59.5 & 418 & 578 & 4.0 \\
$\mathrm{Pt}_{57.3} \mathrm{Cu}_{14.6} \mathrm{Ni}_{5.3} \mathrm{P}_{22.8}$ & {$[22]$} & 13.6 & 62.40 & 352.6 & 479.1 & 3.8 \\
$\mathrm{Pt}_{60} \mathrm{Cu}_{16} \mathrm{Co}_{2} \mathrm{P}_{22}$ & {$[22]$} & 11.8 & 69.2 & 371.4 & 487.0 & 3.8 \\
$\mathrm{Pd}_{43} \mathrm{Cu}_{27} \mathrm{Ni}_{10} \mathrm{P}_{20}$ & {$[25]$} & 10.3 & 76.2 & 446 & 568 & 4.0 \\
\hline
\end{tabular}

Table 3. Adam-Gibbs fitting parameters used to model the equilibrium viscosity data taken from the literature (listed in Table 2) to the Equation (2). The specific heat capacity data used for the description of Equation (6) are taken from the indicated literature. $\mathrm{T}_{\mathrm{m}}{ }^{*}$ is the temperature in Kelvin at which the melt assumes a value of $1 \mathrm{~Pa} s . \mathrm{S}_{\mathrm{c}}\left(\mathrm{T}_{\mathrm{m}}{ }^{*}\right)$ and $\mathrm{C}$ are the Adam-Gibbs fitting parameters in units of $\mathrm{J} /(\mathrm{g}$-atom $\mathrm{K}$ ) and $\mathrm{kJ} /(\mathrm{g}$-atom), respectively.

\begin{tabular}{cccccc}
\hline Material (at\%) & $\mathbf{c}_{\mathbf{p}}$-Data & $\mathbf{T}_{\mathbf{m}}{ }^{*}$ & $\mathbf{S}_{\mathbf{c}}\left(\mathbf{T}_{\mathbf{m}}{ }^{*}\right)$ & $\mathbf{C}$ & $\mathbf{C} / \mathbf{T}_{\mathbf{g}}{ }^{*} \Delta \mathbf{c}_{\mathbf{p}}\left(\mathbf{T}_{\mathbf{g}}{ }^{*}\right)$ \\
\hline $\mathrm{Mg}_{59.5} \mathrm{Cu}_{22.9} \mathrm{Ag}_{6.6} \mathrm{Gd}_{11}$ & {$[45]$} & 825 & 21.17 & 188.79 & 27.2 \\
$\mathrm{Mg}_{65} \mathrm{Cu}_{25} \mathrm{Y}_{10}$ & {$[49]$} & 832 & 18.64 & 155.14 & 23.4 \\
\hline
\end{tabular}


Table 3. Cont.

\begin{tabular}{cccccc}
\hline Material (at\%) & $\mathbf{c}_{\mathbf{p}}$-Data & $\mathbf{T}_{\mathbf{m}}{ }^{*}$ & $\mathbf{S}_{\mathbf{c}}\left(\mathbf{T}_{\mathbf{m}}{ }^{*}\right)$ & $\mathbf{C}$ & $\mathbf{C l}_{\mathbf{g}} \mathbf{T}_{\mathbf{g}}{ }^{*} \Delta \mathbf{c}_{\mathbf{p}}\left(\mathbf{T}_{\mathbf{g}}{ }^{*}\right)$ \\
\hline $\mathrm{Zr}_{46.75} \mathrm{Ti}_{8.25} \mathrm{Cu}_{7.5} \mathrm{Ni}_{10} \mathrm{Be}_{27.5}$ & {$[50]$} & 1198 & 16.46 & 222.68 & 20.5 \\
$\mathrm{Zr}_{41.2} \mathrm{Ti}_{13.8} \mathrm{Cu}_{12.5} \mathrm{Ni}_{10} \mathrm{Be}_{22.5}$ & {$[55]$} & 1228 & 19.07 & 295.11 & 21.0 \\
$\mathrm{Fe}_{67} \mathrm{Mo}_{6} \mathrm{Ni}_{3.5} \mathrm{Cr}_{3.5} \mathrm{P}_{12} \mathrm{C}_{5.5} \mathrm{~B}_{2.5}$ & {$[21]$} & 1454 & 18.68 & 288.62 & 21.5 \\
$\mathrm{Au}_{49} \mathrm{Cu}_{26.9} \mathrm{Si}_{16.3} \mathrm{Ag}_{5.5} \mathrm{Pd}_{2.3}$ & {$[23,42]$} & 755 & 17.56 & 149.71 & 22.5 \\
$\mathrm{Cu}_{47} \mathrm{Ti}_{34} \mathrm{Zr}_{11} \mathrm{Ni}_{8}$ & {$[9]$} & 1282 & 17.46 & 212.83 & 20.6 \\
$\mathrm{Zr}_{58.5} \mathrm{Cu}_{15.6} \mathrm{Ni}_{12.8} \mathrm{Al}_{10.3} \mathrm{Nb}_{2.8}$ & {$[19]$} & 1287 & 12.34 & 207.54 & 19.7 \\
$\mathrm{Pd}_{40} \mathrm{Ni}_{40} \mathrm{P}_{20}$ & {$[53]$} & 1000 & 16.93 & 166.77 & 15.4 \\
$\mathrm{Pt}_{42.5} \mathrm{Cu}_{27} \mathrm{Ni}_{9.5} \mathrm{P}_{21}$ & {$[22]$} & 890 & 19.84 & 197.2 & 15.2 \\
$\mathrm{Ni}_{69} \mathrm{Cr}_{8.5} \mathrm{Nb}_{3} \mathrm{P}_{16.5} \mathrm{~B}_{3}$ & {$[22]$} & 1180 & 15.46 & 200.4 & 15.1 \\
$\mathrm{Pd}_{40} \mathrm{Cu}_{30} \mathrm{Ni}_{10} \mathrm{P}_{20}$ & {$[56]$} & 1017 & 13.07 & 157.35 & 13.9 \\
$\mathrm{Pt}_{57.3} \mathrm{Cu}_{14.6} \mathrm{Ni}_{5.3} \mathrm{P}_{22.8}$ & {$[22]$} & 823 & 19.03 & 178.9 & 13.7 \\
$\mathrm{Pt}_{60} \mathrm{Cu}_{16} \mathrm{Co}_{2} \mathrm{P}_{22}$ & {$[22]$} & 801 & 17.64 & 160.9 & 11.8 \\
$\mathrm{Pd}_{43} \mathrm{Cu}_{27} \mathrm{Ni}_{10} \mathrm{P}_{20}$ & {$[25]$} & 900 & 11.26 & 114.87 & 9.9 \\
\hline
\end{tabular}

\subsection{Kinetic Fragility}

Figure 4 is a plot that represents the kinetic fragility of the studied BMG-forming liquids in the deep undercooled state, i.e., in the vicinity of the glass transition temperature, $\mathrm{T}_{\mathrm{g}}{ }^{*}$. The equilibrium viscosity of the undercooled liquid is plotted against $\mathrm{T}_{\mathrm{g}}{ }^{*} / \mathrm{T}$. The continuous lines are the fits of equilibrium viscosity data to the VFT equation; however a similar fragility plot within the selected range of temperatures can be obtained using the MYEGA equation. The VFT parameter $\mathrm{D}^{*}$ reflects the sensitivity of the viscosity to temperature changes, and higher values correspond to kinetically stronger liquid behavior. In terms of the Adam-Gibbs theory and the MYEGA model a larger $\mathrm{D}^{*}$ value corresponds, as least within the same alloy system, to larger values of the free enthalpy barrier for cooperative rearrangements, $\mathrm{C}$ and $\mathrm{K}$, respectively. Due to the large difference in glass transition temperature between the various alloy systems, a general trend of increasing $\mathrm{K} / \mathrm{H}$ versus increasing $\mathrm{D}^{*}$ is observed; see also the values reported in the Tables.

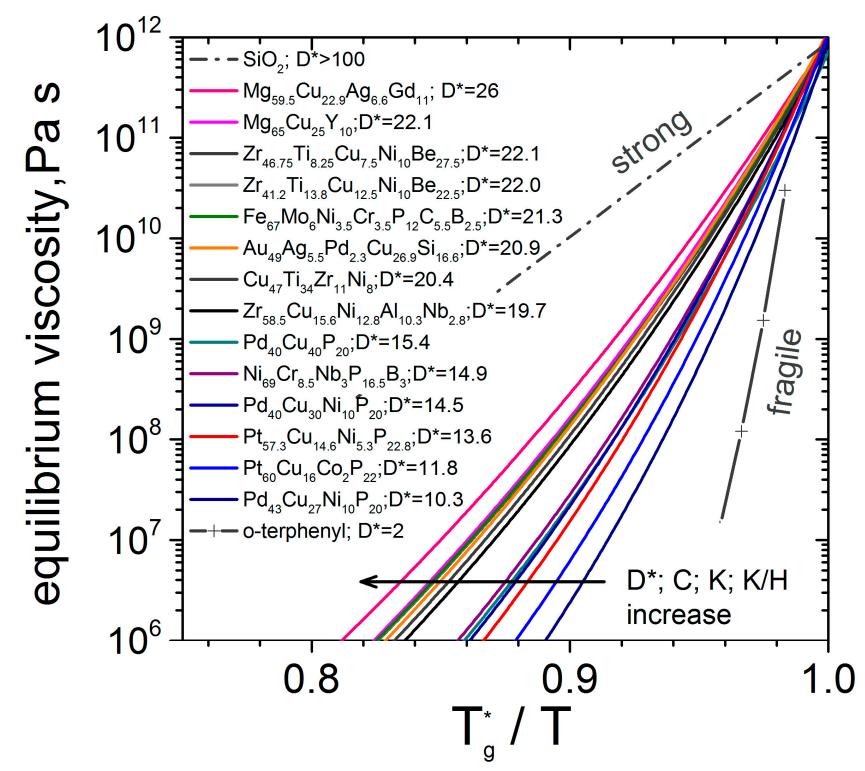

Figure 4. Fragility plot of selected bulk metallic glass forming liquids in comparison to that for $\mathrm{SiO}_{2}$ and o-terphenyl. $\mathrm{T}_{\mathrm{g}}{ }^{*}$ is the temperature at which the supercooled liquid assumes a viscosity value of $10^{12} \mathrm{~Pa}$ s. The continuous lines are the fits of equilibrium viscosity data to the VFT equation. The fragility plots based on MYEGA fits and Adam-Gibbs fits give similar results. D*, C, K and $\mathrm{H}$ are the VFT, Adam-Gibbs, and MYEGA parameters, respectively. 
The Pd-based, the Pt-based, and the $\mathrm{Ni}_{69} \mathrm{Cr}_{8.5} \mathrm{Nb}_{3} \mathrm{P}_{16.5} \mathrm{~B}_{3}$ BMG compositions show a distinctively more fragile behavior than the other BMGs in terms of kinetic fragility. As shown in Figure 4 and in Tables 1 and 2, these liquids have fragility parameter $\mathrm{D}^{*}$ values between 10 and 15 , corresponding to values of fragility index $m$ and $m$ (MYEGA) between 53 and 80. The Mg-based alloys show, in contrast, a distinctively stronger fragility behavior with a high value of $\mathrm{D}^{*}$ between 22 and 26 ( $m$ between 40 and 45 ). The Zr-based BMG alloys always show highly fragile liquid behaviors with a $\mathrm{D}^{*}$ value of approximately 10 when measured at high temperatures in the molten state [41,57]. During undercooling, the Zr-based glass formers undergo a fragile-to-strong transition and the viscosity values measured in the ultra-viscous state in the vicinity of the glass transition are associated with high $\mathrm{D}^{*}$ values similar to those of the Mg-based BMGs [20,33-36]. A similar trend of a high-T fragile liquid vs. a low- $\mathrm{T}$ stronger liquid was also observed with the $\mathrm{Au}_{49} \mathrm{Cu}_{26.9} \mathrm{Si}_{16.3} \mathrm{Ag}_{5.5} \mathrm{Pd}_{2.3}$ composition [23,37] and in several poor metallic glass formers [38-40,58-60].

\subsection{Thermodynamic Fragility}

The thermodynamic fragility of the selected BMGs was studied by means of the Adam-Gibbs relation. For the non-linear fitting procedure with Equation (2), the function used in this work to describe the configurational entropy change, $\mathrm{S}_{\mathrm{C}}(\mathrm{T})$, is the following:

$$
\mathrm{S}_{\mathrm{c}}(\mathrm{T})=\mathrm{S}_{\mathrm{c}}\left(\mathrm{T}_{\mathrm{m}}^{*}\right)-\int_{\mathrm{T}}^{\mathrm{T}_{\mathrm{m}}^{*}}\left(\Delta \mathrm{c}_{\mathrm{p}}^{l-x}\left(\mathrm{~T}^{\prime}\right) / \mathrm{T}^{\prime}\right) \mathrm{dT}^{\prime}
$$

The $S_{C}(T)$ of the liquid is assumed here to decrease from the fixed value $S_{C}\left(T_{m}{ }^{*}\right)$ during undercooling with the same rate as the entropy difference between the liquid and the crystal [25]. Figure 5 shows the rate of change with temperature of the specific heat capacity of the liquid vs. that of a typical crystalline state for one selected BMG composition for each alloy system. With the $\Delta c_{p}{ }^{1-x}(T)$ rates the configurational entropy, $\mathrm{S}_{\mathrm{C}}(\mathrm{T})$, of each glass former can be calculated with Equation (6), as well as the temperature at which the configurational entropy of the liquid vanishes, i.e., $\mathrm{T}_{0}{ }^{*}$. The kinetic $\mathrm{T}_{0}$ and the thermodynamic $\mathrm{T}_{0}$ *are found always similar [25] and indicates that when the barrier with respect to viscous flow would become infinitely large (at $\mathrm{T}_{0}$ ), the liquid would act like a solid that has assumed the ideal packing configuration.

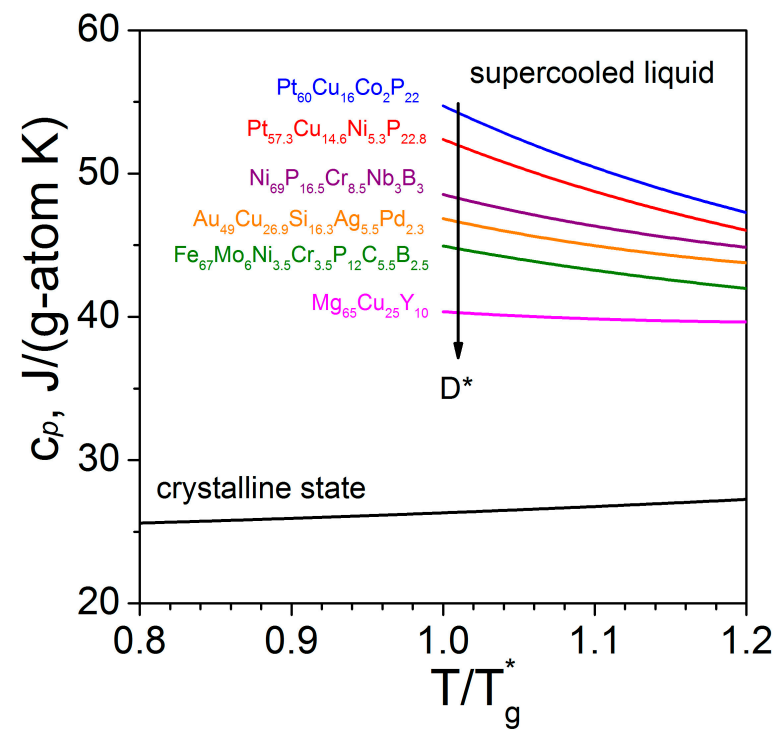

Figure 5. Plot of specific heat capacity for selected BMG forming liquids, as calculated from Equation (4), as a function $\mathrm{T} / \mathrm{T}_{\mathrm{g}}{ }^{*} \cdot \mathrm{T}_{\mathrm{g}}$ is the temperature at which the supercooled liquid assumes a viscosity value of $10^{12}$ Pa s. 
According to Angell, liquids that have a structurally well-defined bonding scheme are restricted in placing particles in space and result in a low density of potential energy minima in comparison to liquids that lack such network bonding schemes [60]. According to the Adam-Gibbs model, a low density of potential minima would imply a more fragile behavior of the viscosity. The short and medium range order found in Zr-based BMG forming liquids $[15,16]$ restricts, from a kinetics point of view, the redistribution of the component elements. Indeed, their high-viscosity values (low atomic mobility) detected in the ultra-high viscous state place the Zr-based systems among the strongest metallic glass-forming liquids.

\subsection{Connection between the Kinetic and the Thermodynamic Fragility}

Based on the notion that the kinetics of the liquid has to be connected to the amount of possible configurations of the liquid, efforts are made to link the kinetics to the thermodynamics of the liquid alloys. For example, Angell generated a fragility plot in which the excess entropy $\Delta c_{p}{ }^{1-x}(T)$ scaled with the value of the excess entropy at the standard glass transition temperature, $\mathrm{T}_{\mathrm{g}}{ }^{*}$, is plotted against $T_{g}{ }^{*} / T$ [28]. Rapid entropy changes are characteristic for fragile behavior. In the vicinity of $T_{g}$, the Adam-Gibbs equation is able to describe fairly well the temperature dependence of the viscosity (see Figure 3), and therefore for that temperature range, one could insert the Adam-Gibbs expression (Equation (2)) into the VFT-equation (Equation (1)) and obtain an expression for the rate of configurational entropy change as

$$
\mathrm{S}_{\mathrm{c}} / \mathrm{dT}=\Delta \mathrm{c}_{\mathrm{p}}^{1-\mathrm{x}}(\mathrm{T}) / \mathrm{T}=\mathrm{C} /\left(\mathrm{T}^{2} \mathrm{~T}_{\mathrm{o}} \mathrm{D}^{*}\right)
$$

If $\mathrm{T}_{\mathrm{g}}{ }^{*}$ is chosen as reference temperature, the $\mathrm{D}^{*}$ parameter can be expressed as (see also [22])

$$
\mathrm{D}^{*}=\mathrm{C} /\left(\mathrm{T}_{\mathrm{g}}^{*} \Delta \mathrm{c}_{\mathrm{p}}^{1-\mathrm{x}}\left(\mathrm{T}_{\mathrm{g}}^{*}\right)\right) \text {. }
$$

In this picture, the fragility of the undercooled liquid should be reflected by the rate at which $\Delta c_{p}{ }^{1-x}(T)$ decreases and this was proved to be true in several other comprehensive works [22,28,61-63]. The slope of $c_{p}(T)$ of the liquid close to $T_{g}$ is also found, experimentally, to be associated with the fragility of a few glass-formers [62].

This work tests the connection between the thermodynamic and the kinetic fragility by considering the Adam-Gibbs C-parameter and the VFT-fragility D*, which according to Equation (8) should be linearly proportional to each other close to $\mathrm{T}_{\mathrm{g}}$. Figure 6 shows that, within the same class of based material, the stronger the glass-forming liquid is, the larger the $C$, and the relation between $D^{*}$ and $C$ is monotonic with a slope of approximately $100\left(\mathrm{~J} \mathrm{~g}\right.$-atom $\left.{ }^{-1}\right)$. Figure 7 shows that when the VFT-fragility parameter $\mathrm{D}^{*}$ is plotted against the C-parameter scaled by $\left[\mathrm{T}_{\mathrm{g}}{ }^{*} \Delta \mathrm{c}_{\mathrm{p}}{ }^{1-\mathrm{x}}\left(\mathrm{T}_{\mathrm{g}}{ }^{*}\right)\right]$, all of the data falls into a master linear curve with approximately unitary slope (0.9) and proves the validity of Equation (8), and thus the connection between the thermodynamic and the kinetic fragility for BMG forming systems.

In the VFT description, the parameter $\mathrm{D}^{*}$ refers to the kinetic fragility of the material and reflects the sensitivity of the viscosity to temperature changes: the most fragile glass-formers have a fragility parameter $\mathrm{D}^{*}$ of around 2, whereas the strongest are on the order of 100 . When the fragility parameter of BMG formers is plotted against the number of components in the alloy, as in Reference [64], the D* increases also monotonically. Extrapolation of the trend down to a one-component system as well to an infinitely small free enthalpy barrier to cooperative rearrangements (as in Figure 7) yields $\mathrm{D}^{*}=2$, which is in excellent agreement with the estimated fragility of pure metals using their melt viscosities and apparent activation energies for flow $[64,65]$. The underlying reason for this behavior is most likely that, with increasing number of differently sized atomic species or complexity of the system, it becomes possible to produce higher and higher density liquids. This results in a lower enthalpic and entropic state of the liquid and thus a relative thermodynamic stabilization with respect to the 
crystal [14-16]. It also makes the liquid more viscous or more "solid-like" and thus stronger in the framework of the fragility concept.

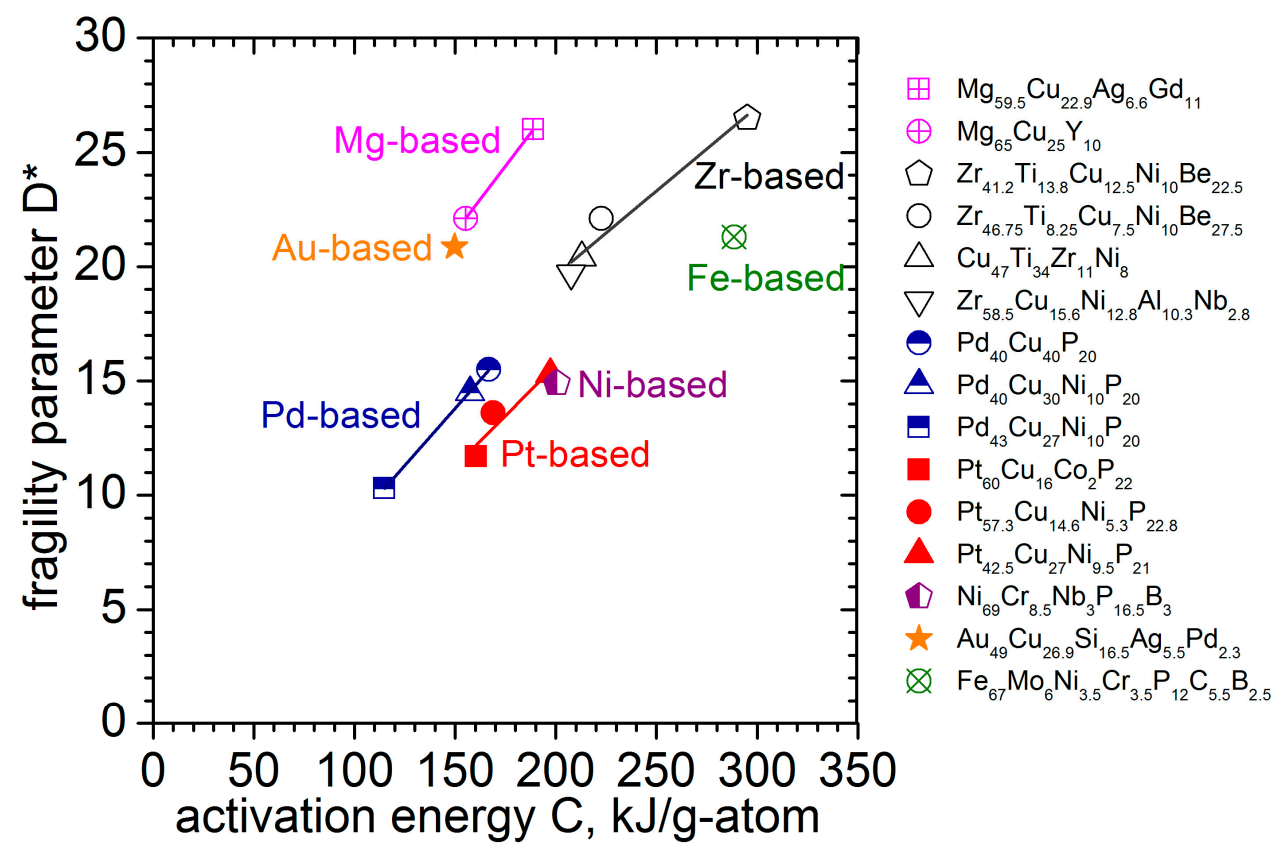

Figure 6. Plot of the kinetic fragility parameter $\mathrm{D}^{*}$ against free activation energy per particle to cooperative rearrangements $C$ of the Adam-Gibbs equation for selected bulk metallic glass forming liquids. The lines are linear fits to the data.

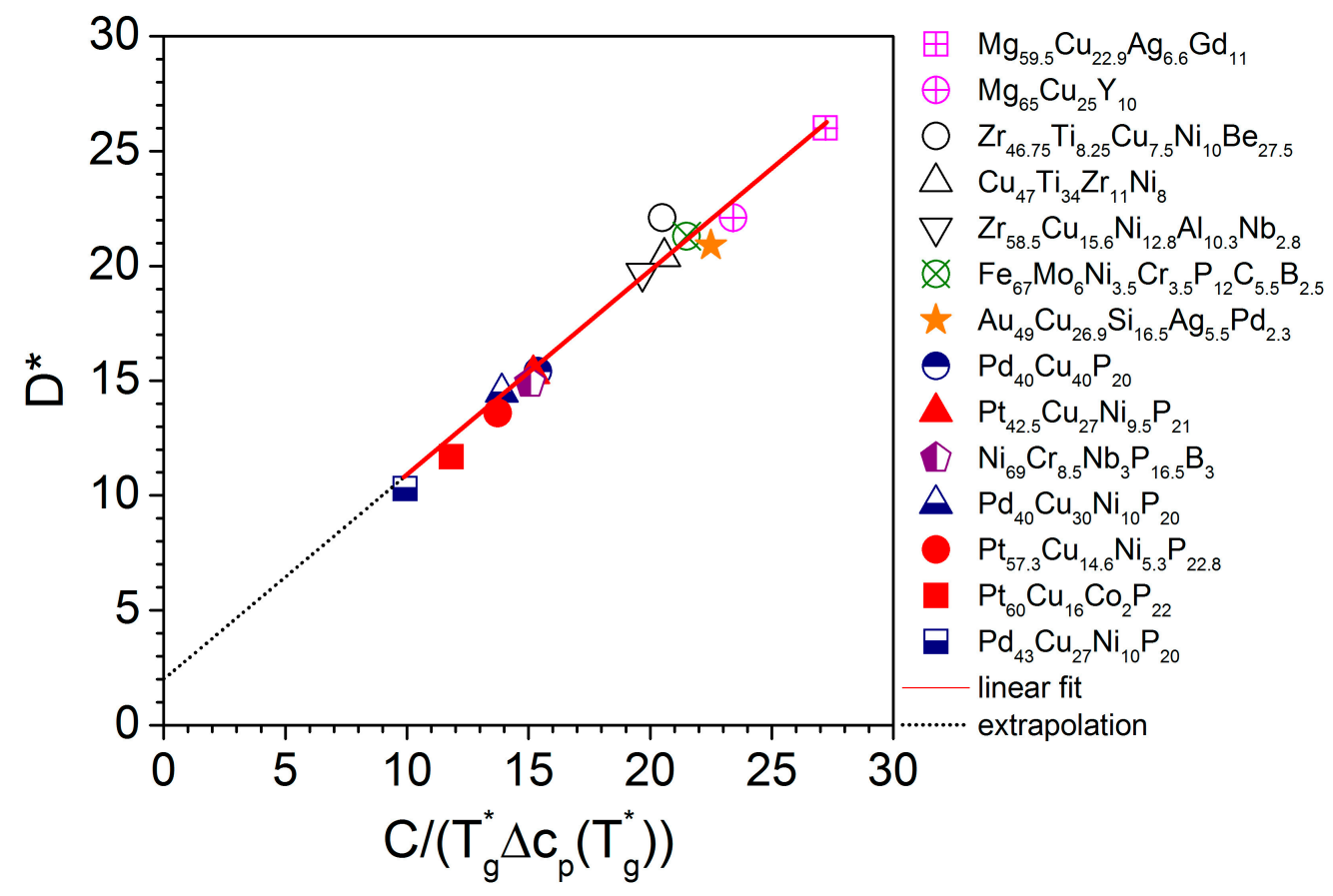

Figure 7. Plot of the kinetic fragility parameter $D^{*}$ against the Adam-Gibbs scaled C-parameter for the selected bulk metallic glass forming liquids. The error bar is smaller than the size of the symbols. The red line is the linear fits to the data with slope value of approximately 0.9 . The extrapolation of the trend to $C=0$ results in $D^{*}=2$. 
Moreover, in terms of the Adam-Gibbs model, $\mathrm{C}$ is the free enthalpy barrier for cooperative rearrangements and it is an important factor which is connected to the small displacement of atoms, while the cooperative group remains the same or at least has the same dependence on temperature as for structural relaxation [60]. $\mathrm{C}$ in this work increases from about $100 \mathrm{~kJ} /(\mathrm{g}$-atom $\mathrm{K})(\sim 1 \mathrm{eV})$ for the most fragile liquids which are the Pd-based compositions to about $300 \mathrm{~kJ} /(\mathrm{g}$-atom $\mathrm{K})(\sim 3 \mathrm{eV})$ for the strongest Zr-based alloys. These values compare well to the activation energies for diffusion in metallic glasses around the glass transition temperature of about $1 \mathrm{eV}$ for small atoms and $3 \mathrm{eV}$ for large atoms [66]. If the fragile $\mathrm{Pd}-, \mathrm{Pt}-$, and $\mathrm{Ni}$-based BMG forming liquids require a lower activation barrier, the atomic flow or the relaxation event in these systems should be less localized and its characteristic activation barrier more reflective of the involvement of the smaller atomic species [67-71]. In this sense, they can be considered as more "liquid-like" than the Zr-based BMG forming liquids.

\section{Conclusions}

This work shows that we have clear experimental evidence that the kinetic fragility of ultra-viscous deeply undercooled metallic liquids is directly connected to the temperature dependence of the thermodynamic functions being satisfactory described be the Adam-Gibbs theory. The Pd-, Pt-, and Ni-based BMG-formers behave kinetically more fragile than the Mg-based and the $\mathrm{Zr}$ - based BMG alloys. An overall larger trend of the excess specific heat for the more fragile supercooled liquids is experimentally observed than for the strong liquids. This is reflected by the temperature dependence of the excess entropies, which decreases most rapidly for the fragile liquids and therefore leads to a more non-Arrhenius-like behavior in the Adam-Gibbs equation. It can furthermore be noted that cooperative arrangements of the atoms during flow is more difficult for stronger liquids than for fragile liquids. As shown in Figures 6 and 7, the activation energy for cooperative rearrangements, C, in the Adam-Gibbs equation rises with increasing fragility parameter.

Acknowledgments: The author is grateful for long time collaborations and intensive discussions with R. Busch, O. Gross, Z. Evenson, S. Hechler, M. Frey, M. Stolpe, S. Wei, and acknowledges the support of the German Research Foundation (DFG) (GA1721/2-2).

Conflicts of Interest: The author declares no conflict of interest.

\section{References}

1. Zhang, T.; Inoue, A.; Masumoto, T. Amorphous Zr-Al-Tm (Tm = Co, Ni, Cu) Alloys with Significant Supercooled Liquid Region of over 100-K. Mater. Trans. JIM 1991, 32, 1005-1010. [CrossRef]

2. Inoue, A.; Nakamura, T.; Nishiyama, N.; Masumoto, T. Mg-Cu-Y Bulk Amorphous Alloys with High Tensile Strength Produced by a High-Pressure Die Casting Method. Mater. Trans. JIM 1992, 33, 937-945. [CrossRef]

3. Lin, X.H.; Johnson, W.L. Formation of Ti-Zr-Cu-Ni bulk metallic glasses. J. Appl. Phys. 1995, 78, 6514-6519. [CrossRef]

4. Schroers, J.; Johnson, W.L. Highly Processable Bulk Metallic Glass-forming alloys in the Pt-Co-Ni-Cu-P system. Appl. Phys. Lett. 2004, 84, 3666. [CrossRef]

5. Schroers, J.; Lohwongwatana, B.; Johnson, W.L.; Peker, A. Gold based bulk metallic glass. Appl. Phys. Lett. 2005, 87, 2005-2007. [CrossRef]

6. Na, J.H.; Floyd, M.; Garrett, G.; Demetriou, M.D.; Johnson, W.L. Bulk Metallic Steel with High Glass Forming Ability. U.S. Patent 2015/0020929 A1, 22 January 2015.

7. Na, J.H.; Demetriou, M.D.; Floyd, M.; Hoff, A.; Garrett, G.R.; Johnson, W.L. Compositional landscape for glass formation in metal alloys. Proc. Natl. Acad. Sci. USA 2014, 111, 9031-9036. [CrossRef] [PubMed]

8. Peker, A.; Johnson, W.L. A highly processable metallic glass: Zr41.2Ti 13.8Cu12.5Ni10.0Be22.5. Appl. Phys. Lett. 1993, 63, 2342-2344. [CrossRef]

9. Glade, S.C.; Busch, R.; Lee, D.S.; Johnson, W.L.; Wunderlich, R.K.; Fecht, H.J.; Introduction, I. Thermodynamics of Cu47Ti34Zr11Ni8, Zr52.5Cu17.9Ni14.6Al10Ti5 and Zr57Cu15.4Ni12.6Al10Nb5 bulk metallic glass forming alloys. J. Appl. Phys. 2000, 87, 7242-7248. [CrossRef] 
10. Hays, C.C.; Schroers, J.; Johnson, W.L.; Rathz, T.J.; Hyers, R.W.; Rogers, J.R.; Robinson, M.B. Vitrification and determination of the crystallization time scales of the bulk-metallic-glass-forming liquid Zr58.5Nb2.8Cu15.6Ni12.8Al 10.3. Appl. Phys. Lett. 2001, 79, 1605-1607. [CrossRef]

11. Lin, X. Bulk Glass Formation and Crystallization of Zr-Ti Based Alloy. Ph.D. Thesis, California Institute of Technology, Pasadena, CA, USA, 1997.

12. Gross, O.; Gallino, I.; Busch, R.; Eisenbart, M.; Klotz, U.E. Massivglasbildende Weißgoldlegierung. Patent DE202016004123 (U1), 12 July 2016.

13. Johnson, W.L. Bulk glass-forming metallic alloys-Science and technology. MRS Bull. 1999, 24, 42-56. [CrossRef]

14. Busch, R. The thermophysical properties of bulk metallic glass-forming liquids. JOM 2000, 52, 39-42. [CrossRef]

15. Busch, R.; Gallino, I. On the kinetic, thermodynamics and structure of bulk metallic glass forming liquids. JOM Spec. Issue Amorph. Alloy 2017. [CrossRef]

16. Busch, R.; Schroers, J.; Wang, W.H. Thermodynamics and Kinetics of Bulk Metallic Glass. MRS Bull. 2007, 32, 620-623. [CrossRef]

17. Inoue, A. Stabilization of metallic supercooled liquid and bulk amorphous alloys. Acta Mater. 2000, 48, 279-306. [CrossRef]

18. Busch, R.; Bakke, E.; Johnson, W.L. Viscosity of the supercooled liquid and relaxation at the glass transition of the Zr46.75Ti8.25Cu7.5Ni10Be27.5 bulk metallic glass forming alloy. Acta Mater. 1998, 46, 4725-4732. [CrossRef]

19. Gallino, I.; Shah, M.B.; Busch, R. Enthalpy relaxation and its relation to the thermodynamics and crystallization of the Zr58.5Cu15.6Ni12.8Al10.3Nb2.8 bulk metallic glass-forming alloy. Acta Mater. 2007, 55, 1367-1376. [CrossRef]

20. Evenson, Z.; Busch, R. Equilibrium viscosity, enthalpy recovery and free volume relaxation in a Zr44Ti11Ni10Cu10Be25 bulk metallic glass. Acta Mater. 2011, 59, 4404-4415. [CrossRef]

21. Bochtler, B.; Gross, O.; Gallino, I.; Busch, R. Thermo-physical characterization of the Fe67Mo6Ni3.5Cr3.5P12C5.5B2.5 bulk metallic glass forming alloy. Acta Mater. 2016, 118, 129-139. [CrossRef]

22. Gross, O.; Bochtler, B.; Stolpe, M.; Hechler, S.; Hembree, W.; Busch, R.; Gallino, I. The kinetic fragility of Pt-Pand Ni-P-based bulk glass-forming liquids and its thermodynamic and structural signature. Acta Mater. 2017, 132, 118-127. [CrossRef]

23. Gallino, I.; Cangialosi, D.; Evenson, Z.; Schmitt, L.; Hechler, S.; Stolpe, M.; Ruta, B. Activation energy spectrum for relaxation and polyamorphism in an ultra-viscous metallic glass former. arXiv 2017, arXiv:1706.03830.

24. Angell, C.A. Formation of glasses from liquids and biopolymers. Science 1995, 267, 1924-1935. [CrossRef] [PubMed]

25. Gallino, I.; Schroers, J.; Busch, R. Kinetic and thermodynamic studies of the fragility of bulk metallic glass forming liquids. J. Appl. Phys. 2010, 108, 1-9. [CrossRef]

26. Adam, G.; Gibbs, J.H. On the Temperature Dependence of Cooperative Relaxation Properties in Glass-Forming Liquids. J. Chem. Phys. 1965, 43, 139-146. [CrossRef]

27. Goldstein, M. Viscous liquids and the glass transition: A potential energy barrier picture. J. Chem. Phys. 1969, 51, 3728-3739. [CrossRef]

28. Martinez, L.-M.; Angell, C.A. A thermodynamic connection to the fragility of glass-forming liquids. Nature 2001, 410, 663-667. [CrossRef] [PubMed]

29. Mauro, J.C.; Yue, Y.; Ellison, A.J.; Gupta, P.K.; Allan, D.C. Viscosity of glass-forming liquids. Proc. Natl. Acad. Sci. USA 2009, 106, 19780-19784. [CrossRef] [PubMed]

30. Naumis, G.G. Glass transition phenomenology and flexibility: An approach using the energy landscape formalism. J. Non-Cryst. Solids 2006, 352, 4865-4870. [CrossRef]

31. Phillips, J.C.; Thorpe, M.F. Constraint theory, vector percolation and glass formation. Solid State Commun. 1985, 53, 699-702. [CrossRef]

32. Gupta, P.K.; Mauro, J.C. Composition dependence of glass transition and fragility. I. A topological model incorporating temperature-dependent constraints. J. Chem. Phys. 2009, 130, 1-8. [CrossRef] [PubMed] 
33. Evenson, Z.; Raedersdorf, S.; Gallino, I.; Busch, R. Equilibrium viscosity of Zr-Cu-Ni-Al-Nb bulk metallic glasses. Scr. Mater. 2010, 63, 573-576. [CrossRef]

34. Wei, S.; Yang, F.; Bednarcik, J.; Kaban, I.; Shuleshova, O.; Meyer, A.; Busch, R. Liquid-liquid transition in a strong bulk metallic glass-forming liquid. Nat. Commun. 2013, 4, 1-9. [CrossRef] [PubMed]

35. Stolpe, M.; Jonas, I.; Wei, S.; Evenson, Z.; Hembree, W.; Yang, F.; Meyer, A.; Busch, R. Structural changes during a liquid-liquid transition in the deeply undercooled $\mathrm{Zr} 58.5 \mathrm{Cu} 15.6 \mathrm{Ni1} 2.8 \mathrm{Al} 10.3 \mathrm{Nb} 2.8$ bulk metallic glass forming melt. Phys. Rev. B Condens. Matter Mater. Phys. 2016, 93, 1-7. [CrossRef]

36. Lan, S.; Blodgett, M.; Kelton, K.F.; Ma, J.L.; Fan, J.; Wang, X.-L. Structural crossover in a supercooled metallic liquid and the link to a liquid-to-liquid phase transition. Appl. Phys. Lett. 2016, 108, 211907. [CrossRef]

37. Hechler, S.; Ruta, B.; Stolpe, M.; Pineda, E.; Evenson, Z.; Gross, O.; Hembree, W.; Bernasconi, A.; Busch, R.; Gallino, I. Liquid-liquid transition revealed by quasi-static cooling of an ultra-viscous metallic liquid. arXiv 2017, arXiv:1704.06703.

38. Zhou, C.; Hu, L.; Sun, Q.; Zheng, H.; Zhang, C.; Yue, Y. Structural evolution during fragile-to-strong transition in $\mathrm{CuZr}$ (Al) glass-forming liquids. J. Chem. Phys. 2015, 142, 64508. [CrossRef] [PubMed]

39. Orava, J.; Weber, H.; Kaban, I.; Greer, A.L. Viscosity of liquid Ag-In-Sb-Te: Evidence of a fragile-to-strong crossover. J. Chem. Phys. 2016, 144, 194503. [CrossRef] [PubMed]

40. Zhang, C.; Hu, L.; Yue, Y.; Mauro, J.C. Fragile-to-strong transition in metallic glass-forming liquids. J. Chem. Phys. 2010, 133, 1-7. [CrossRef] [PubMed]

41. Way, C.; Wadhwa, P.; Busch, R. The influence of shear rate and temperature on the viscosity and fragility of the Zr41.2Ti13.8Cu12.5Ni10.0Be22.5 metallic-glass-forming liquid. Acta Mater. 2007, 55, 2977-2983. [CrossRef]

42. Evenson, Z. On the Thermodynamic and Kinetic Properties of Bulk Glass Forming Metallic Systems. Ph.D. Thesis, Saarland University, Saarbrücken, Germany, 2012.

43. Legg, B.A.; Schroers, J.; Busch, R. Thermodynamics, kinetics, and crystallization of Pt57.3Cu14.6Ni5.3P22.8 bulk metallic glass. Acta Mater. 2007, 55, 1109-1116. [CrossRef]

44. Eisenbart, M.; Klotz, U.E.; Busch, R.; Gallino, I. A colourimetric and microstructural study of the tarnishing of gold-based bulk metallic glasses. Corros. Sci. 2014, 85, 258-269. [CrossRef]

45. Frey, M. Thermodynamic and Kinetic Properties of Magnesium-Based Bulk Metallic Glass-Forming Liquids. Master of Science Thesis, Saarland University, Saarbrücken, Germany, 2016.

46. Inaba, S.; Oda, S.; Morinaga, K. Heat capacity of oxide glasses at high temperature region. J. Non-Cryst. Solids 2003, 325, 258-266. [CrossRef]

47. Hecksher, T.; Nielsen, A.I.; Olsen, N.B.; Dyre, J.C. Little evidence for dynamic divergences in ultraviscous molecular liquids. Nat. Phys. 2008, 4, 737-741. [CrossRef]

48. Dyre, J.C.; Hecksher, T.; Niss, K. A brief critique of the Adam-Gibbs entropy model. J. Non-Cryst. Solids 2009, 355, 624-627. [CrossRef]

49. Busch, R.; Liu, W.; Johnson, W.L. Thermodynamics and kinetics of the $\mathrm{Mg}_{65} \mathrm{Cu}_{25} \mathrm{Y}_{10}$ bulk metallic glass forming liquid. J. Appl. Phys. 1998, 83, 4134-4141. [CrossRef]

50. Bakke, E.; Busch, R.; Johnson, W.L. The viscosity of the Zr46.75Ti8.25Cu7.5Ni10Be27.5 bulk metallic glass forming alloy in the supercooled liquid. Appl. Phys. Lett. 1995, 67, 3260. [CrossRef]

51. Waniuk, T.A.; Busch, R.; Masuhr, A.; Johnson, W.L. Equilibrium viscosity of the Zr41.2Ti13.8Cu12.5Ni10Be22.5 bulk metallic glass-forming liquid and viscous flow during relaxation, phase separation, and primary crystallization. Acta Mater. 1998, 46, 5229-5236. [CrossRef]

52. Glade, S.C.; Johnson, W.L. Viscous flow of the $\mathrm{Cu}_{47} \mathrm{Ti}_{34} \mathrm{Zr}_{11} \mathrm{Ni}_{8}$ glass forming alloy. J. Appl. Phys. 2000, 87, 7249-7251. [CrossRef]

53. Willnecker, R.; Wilde, G.; Go, G.P.; Fecht, H.J.; Introduction, I. Calorimetric, thermomechanical, and rheological characterizations of bulk glass-forming Pd 40 Ni 40 P 20. J. Appl. Phys. 2000, 87, 1141-1152.

54. Nishiyama, N.; Inoue, A. Glass Transition Behavior and Viscous Flow Working of Pd40Cu30Ni10P20 Amorphous Alloy. Mater. Trans. JIM 1999, 40, 65-71. [CrossRef]

55. Busch, R.; Kim, Y.J.; Johnson, W.L. Thermodynamics and Kinetics of the Undercooled Liquid and the Glass Transition of the Zr41.2Ti13.8Cu12.5Ni10.0Be22.5 Alloy. J. Appl. Phys. 1995, 77, 4039-4043. [CrossRef]

56. Lu, I.-R.; Wilde, G.; Görler, G.; Willnecker, R. Thermodynamic properties of Pd-based glass-forming alloys. J. Non-Cryst. Solids 1999, 250-252, 577-581. [CrossRef] 
57. Evenson, Z.; Schmitt, T.; Nicola, M.; Gallino, I.; Busch, R. High temperature melt viscosity and fragile to strong transition in $\mathrm{Zr}-\mathrm{Cu}-\mathrm{Ni}-\mathrm{Al}-\mathrm{Nb}(\mathrm{Ti})$ and $\mathrm{Cu} 47 \mathrm{Ti} 34 \mathrm{Zr} 11 \mathrm{Ni} 8$ bulk metallic glasses. Acta Mater. 2012, 60, 4712-4719. [CrossRef]

58. Zhou, C.; Hu, L.; Sun, Q.; Qin, J.; Bian, X.; Yue, Y. Indication of liquid-liquid phase transition in CuZr-based melts. Appl. Phys. Lett. 2013, 103. [CrossRef]

59. Wei, S.; Gallino, I.; Busch, R.; Angell, C.A. Glass transition with decreasing correlation length during cooling of Fe50Co50 superlattice and strong liquids. Nat. Phys. 2011, 7, 178-182. [CrossRef]

60. Angell, C. Relaxation in liquids, polymers and plastic crystals—Strong/fragile patterns and problems. J. Non-Cryst. Solids 1991, 131-133, 13-31. [CrossRef]

61. Fontana, G.D.; Battezzati, L. Thermodynamic and dynamic fragility in metallic glass-formers. Acta Mater. 2013, 61, 2260-2267. [CrossRef]

62. Wei, S.; Evenson, Z.; Gallino, I.; Busch, R. The impact of fragility on the calorimetric glass transition in bulk metallic glasses. Intermetallics 2014, 55, 138-144. [CrossRef]

63. Smedskjaer, M.M.; Mauro, J.C.; Youngman, R.E.; Hogue, C.L.; Potuzak, M.; Yue, Y. Topological Principles of Borosilicate Glass Chemistry. J. Phys. Chem. B 2011, 115, 12930-12946. [CrossRef] [PubMed]

64. Shadowspeaker, L.; Busch, R. On the fragility of Nb-Ni-based and Zr-based bulk metallic glasses. Appl. Phys. Lett. 2004, 85, 2508-2510. [CrossRef]

65. Lida, T.; Guthrie, R.I.L. The Physical Properties of Liquid Metals; Clarendon: Oxford, UK, 1988.

66. Faupel, F.; Frank, W.; Macht, M.-P.; Mehrer, H.; Naundorf, V.; Rätzke, K.; Schober, H.R.; Sharma, S.K.; Teichler, H. Diffusion in metallic glasses and supercooled melts. Rev. Mod. Phys. 2003, 75, 237-280. [CrossRef]

67. Argon, A.S.; Kuo, H.Y. Plastic flow in a disordered bubble raft (an analog of a metallic glass). Mater. Sci. Eng. 1979, 39, 101-109. [CrossRef]

68. Egami, T. Structural relaxation in metallic glasses. Ann. N.Y. Acad. Sci. 1981, 371, 238-251. [CrossRef]

69. Srolovitz, D.; Vitek, V.; Egami, T. An atomistic study of deformation of amorphous metals. Acta Metall. 1983, 31, 335-352. [CrossRef]

70. Fan, Y.; Iwashita, T.; Egami, T. How thermally activated deformation starts in metallic glass. Nat. Commun. 2014, 5, 5083. [CrossRef] [PubMed]

71. Bartsch, A.; Rätzke, K.; Meyer, A.; Faupel, F. Dynamic Arrest in Multicomponent Glass-Forming Alloys. Phys. Rev. Lett. 2010, 104, 195901. [CrossRef] [PubMed] 